\title{
Dental Education and Practice in India
}

Dentistry in India started with quack trained pupil in China and other countries. This was followed by skilled persons obtaining certificate and licensed training courses in overseas countries. These handful people gained vast experience in dental practice. Graduate courses started with the help of these skilled persons. Initially, the course of training was of small duration which increased with widening of knowledge and skills to 5 years course as on today.

Graduates in dentistry from India and outside India underw ent training in some specialities gaining fellowship/diploma/ certificate in these specialties with skill. Then they started postgraduation in some subject and expanded to nine subjects in dentistry as on today.

With availability of increased knowledge and advanced equipments, each of the specialties expanded its horizon to make this course as 3 years. General dental practitioners have to cope up with this know ledge and skill for which certificate and diploma courses in each specialty are being conducted like endodontics, implantology, geratric, forensic dentistry, esthetic dentistry, etc.

With further expansion of knowledge and skill, starting of super-specialty courses has become necessary. R obotic endoscopic and laser surgeries are also coming up in large way which further adds to the needs of super-specialty backed by demand of such specialties in U rban population of India. D ental practitioners acquiring this knowledge and skills started giving benefit of these special treatments to the patients. A ddition of advanced equipments made it easy to provide advanced treatment to the patients. Simultaneously, dental diseases and treatment awareness also increased in Indian society. This in combination with increase in number of dentists, also has started providing treatment in rural areas up to the level of talukas, which is very likely to reach the villages.

L ooking at the overall scenario, starting of super-specialty courses, progressive research in dentistry, development of advanced equipments and dental services to common man in rural areas, is the future of dentistry in India.

RS Dolas

Dean, Faculty of Dentistry Professor and Head

Department of Oral and M axillofacial Surgery

Dr DY Patil Vidyapeeth

DrDY Patil Dental College and Hospital

Pimpri, Pune, M aharashtra, India 